\title{
Reoperation rates for symptomatic nonunions in posterior cervical (subaxial) fusions with and without bone morphogenetic protein in a cohort of 1158 patients
}

\author{
Kern H. Guppy, MD, PhD, ${ }^{1}$ Jessica Harris, MS, RD, ${ }^{2}$ Jason Chen, MA, ${ }^{2}$ Elizabeth W. Paxton, MA, ${ }^{2}$ \\ Julie Alvarez, $\mathrm{MPH},{ }^{2}$ and Johannes Bernbeck, $\mathrm{MD}^{3}$
}

\begin{abstract}
'Department of Neurosurgery, Kaiser Permanente Medical Group, Sacramento; ${ }^{2}$ Surgical Outcomes \& Analysis Unit of Clinical Analysis, Kaiser Permanente, San Diego; and ${ }^{3}$ Department of Orthopaedics, Kaiser Permanente Southern California, Baldwin Park, California
\end{abstract}

OBJECTIVE Bone morphogenetic protein (BMP) was first approved in 2002 for use in single-level anterior lumbar fusions as an alternative to iliac crest grafts. Subsequent studies have concluded that BMP provides superior fusions rates and therefore reduces reoperations for nonunions. The purpose of this study was to determine the reoperation rates for symptomatic nonunions in posterior cervical (subaxial) spinal fusions with and without the use of BMP and to determine if the nonunion rates are statistically significantly different between the two groups.

METHODS Between January 2009 and September 2013, the authors identified 1158 posterior cervical spinal fusion cases in the subaxial spine (C2-7) from a large spine registry (Kaiser Permanente). Patient characteristics, diagnoses, operative times, lengths of stay, and reoperations were extracted from the registry. Reoperations for symptomatic nonunions were adjudicated via chart review. Logistic regression was conducted to produce estimates of odds ratios (OR) and $95 \%$ confidence intervals (Cls). Kaplan-Meier curves for the non-BMP and BMP groups were generated and compared using the log-rank test.

RESULTS In this cohort there were 1158 patients (19.3\% with BMP) with a median follow up of 1.7 years (interquartile range [IQR] 0.7-2.9 years) and median duration to operative nonunion of 0.63 years (IQR 0.44-1.57 years). KaplanMeier curves showed no significant difference in reoperation rates for nonunions using the log-rank test $(p=0.179)$. In a subset of patients with more than 1 year of follow-up, 788 patients were identified ( $22.5 \%$ with BMP) with a median follow-up duration of 2.5 years (IQR 1.7-3.4 years) and a median time to operative nonunion of 0.73 years (IQR $0.44-1.57$ years). There was no statistically significant difference in the symptomatic operative nonunion rates for posterior cervical (subaxial) fusions with BMP compared with non-BMP (1.1\% vs 0.7\%; crude OR $1.73,95 \% \mathrm{Cl} 0.32-9.55, p=0.527)$ for more than 1 year of follow-up.

CONCLUSIONS This study presents the largest series of patients using BMP in posterior cervical (subaxial) spinal fusions. Reoperation rates for symptomatic nonunions with more than 1 year of follow-up were found to be $1.1 \%$ with BMP and $0.7 \%$ without BMP. There was no significant difference in the reoperation rates for symptomatic nonunions with or without BMP.

http://thejns.org/doi/abs/10.3171/2015.7.SPINE15353

KEY WORDS posterior cervical fusion; reoperation; pseudarthrosis; nonunion; spine registry; retrospective; subaxial cervical spine; bone morphogenetic protein

$\mathrm{R}$ ECOMBINANT human bone morphogenetic protein (rhBMP-2, or BMP, INFUSE, Medtronic) was approved in 2002 by the US FDA for use in anterior lumbar interbody fusion surgery as an alternative to iliac crest bone graft (ICBG) ${ }^{5,7}$ One year later, BMP-7 (OP-1, Stryker) was also approved by the FDA for posterolateral lumbar arthrodesis in degenerative spondylolisthesis as an alternative to ICBG ${ }^{44}$ Over the following decade, the use of BMP in all spinal fusions in the US increased from $0.6 \%$ in 2002 to $26.9 \%$ in $2011 .{ }^{37}$ This was due, in part, to several published papers showing the beneficial effects of using BMP outside the initial FDA guidelines (off-label). By the end of 2010 at least $85 \%$ of the use of BMP was for off-label applications. ${ }^{31} \mathrm{~A}$ few of these studies advocated

ABBREVIATIONS ASA = American Society of Anesthesiologists; $\mathrm{BMI}=$ body mass index; $\mathrm{BMP}=$ bone morphogenetic protein; ICBG = iliac crest bone graft; ICD-9-CM = International Classification of Diseases, Ninth Revision, Clinical Modification; LOS = length of stay.

SUBMITTED March 28, 2015. ACCEPTED July 29, 2015.

INCLUDE WHEN CITING Published online January 1, 2016; DOI: 10.3171/2015.7.SPINE15353. 
for the use of BMP in posterior cervical fusions due to high fusion rates. ${ }^{4,13,20,22,30,47}$ Controversy surrounding its use has also increased over the years ${ }^{17,36}$ with several studies reporting complications $3,8,10,27,35,39-41,45,46,48$ and the FDA issuing a safety alert for the off-label use of BMP in the cervical spine in July $2008 .^{42}$

One of the justifications for the use of BMP has been the cost savings associated with prevention of fusion failures. ${ }^{1,18,33}$ Many of these studies defined fusion rates based solely on radiographic studies. However, several studies $^{9,12,16,24,38}$ have shown that radiographic nonunions do not necessarily translate into symptomatic nonunions. Dawson et al. ${ }^{12}$ and Singh et al..$^{38}$ noted the radiographic definition of "nonunion" may have been too stringent in many studies presented in the literature and may not be representative of normal clinical practices. As an alternative, we believe reoperation rates for symptomatic nonunions is one measure that combines clinical and radiographic findings and is an important outcome measure for patients and health care payers, and would be worthy of adding to the literature.

The objective of this study was to report the reoperation rates for symptomatic nonunions in a large cohort of patients with posterior cervical fusions involving the subaxial cervical spine (C2-7) from a spine registry and to compare the difference in reoperation rates for symptomatic nonunions with and without the use of BMP.

\section{Methods \\ Study Population}

In 2009, Kaiser Permanente, a large, integrated, US health care system with more than 9 million members serving 8 states and the District of Columbia, developed a spine registry to track instrumented spinal fusions. The registry tracks procedures that use spinal implants including anterior cervical plates, interbody devices, pedicle and lateral mass screws, total disc replacement devices, and BMP. The data collection and validation process has been previously described. ${ }^{19,32}$ In brief, using electronic medical record data and a combination of spinal procedural codes from the International Classification of Diseases, Ninth Revision, Clinical Modification (ICD-9-CM) and manufacturers' implant catalog reference numbers, as well as chart review, patients who underwent instrumented spinal fusion were identified. Electronic screening algorithms were used to determine reoperations and revisions from the index spinal procedure. Adjudication via chart review following guidelines from the Centers for Disease Control and Prevention and the Agency for Healthcare Research and Quality was used to identify complications. Patient age, sex, body mass index (BMI), American Society of Anesthesiologists (ASA) score, operative time, length of stay (LOS), diagnosis, region of the spine fused, number of spine levels fused, implant characteristics, procedural information, and outcomes (i.e., complications, revisions, and reoperations) were captured in the registry.

\section{Data Collection}

Using the registry data, we identified all patients who underwent spine surgery using lateral mass or pedicle screws with or without BMP in the subaxial cervical spine. The time period for this data collection spanned January 1, 2009, to September 30, 2013. Patients who received occipitocervical, $\mathrm{Cl}-2$, and cervicothoracic spinal fusions were excluded, hence only identifying a cohort of patients with subaxial cervical (C2-7) spinal fusions. The length of follow-up was determined from the date of surgery to the end of the study period, the end of health plan membership, or death. A subset of patients was identified with more than 1 year of follow-up.

Reoperations were defined as all spine surgeries subsequent to the index spinal fusion within the study period. The review of electronic medical records including imaging was completed on all the reoperation cases by the 2 senior authors (K.H.G. and J.B.) to accurately identify the reason for the reoperation. Reoperations were typically undertaken for infections, seromas, inadequate decompression, hardware failures (including loose screws), adjacent-segment disease, and nonunions. Nonunions were identified based on the surgeons' preoperative and operative notes as well as imaging. The authors used the criteria described in the study by Doward et al., ${ }^{13}$ which combines the criteria of Lenke et al. ${ }^{26}$ and peri-implant radiolucency as a sign of a nonunion. We did not find any discrepancies in the indications for nonunions from the spine surgeons in the subaxial cervical spine cohort among the 7 operative nonunion cases.

\section{Statistical Analysis}

Descriptive statistics (means, medians, standard deviations, interquartile range [IQR], and percentages) for the non-BMP and BMP groups were calculated and compared using the Pearson's chi-square, Fisher's exact, and Wilcoxon rank-sum tests. Logistic regression was conducted to produce estimates of odds ratios (ORs) and 95\% confidence intervals (CIs). Kaplan-Meier curves for the BMP and non-BMP groups were generated and compared using the log-rank test. Either death or ending health plan membership constituted a censored case. Data analysis was performed using SAS software (version 9.4, SAS Institute). Statistical significance was defined as $\alpha=0.05$.

\section{Results}

\section{Patient Characteristics}

We identified 1158 instrumented posterior cervical fusion cases between January 1, 2009, and September 30, 2013 (Table 1), with a median follow-up of 1.7 years (IQR $0.7-2.9$ years). The median duration of time between the index surgery and revision surgery was 0.63 years (IQR $0.44-1.57$ years). The non-BMP and BMP groups significantly differed in age, operative time, number of levels fused, admitting diagnosis, smoking history, and history of diabetes. The distribution of sex, BMI, length of stay, and ASA score were not significantly different.

In the entire patient cohort, $2.9 \%$ of patients $(n=34)$ were lost to follow-up due to death and $4.7 \%(n=54)$ due to insurance termination (Fig. 1). In addition, 282 patients did not reach more than 1 year of follow-up, resulting in a subgroup cohort of 788 patients, with $22.5 \%$ of these patients using BMP (Table 2). In this subset we found a median follow-up duration of 2.5 years (IQR 1.7-3.4 years) 
TABLE 1. Demographics of all patients with posterior cervical (subaxial) fusions with and without BMP

\begin{tabular}{|c|c|c|c|c|}
\hline Demographics & All Cases (\%) & Non-BMP (\%) & BMP (\%) & p Value* \\
\hline Cases & $1158(100.0)$ & $935(80.7)$ & $223(19.3)$ & \\
\hline Age (yrs) & & & & $0.003 \dagger$ \\
\hline Median & 64 & 64 & 61 & \\
\hline IQR & $56-72$ & $56-72$ & $54-69$ & \\
\hline Sex & & & & $0.793 \ddagger$ \\
\hline Female & $505(43.6)$ & $406(43.4)$ & $99(44.4)$ & \\
\hline Male & $653(56.4)$ & $529(56.6)$ & $124(55.6)$ & \\
\hline BMI & & & & $0.224 \S$ \\
\hline$<30$ & $738(63.7)$ & $585(62.6)$ & $153(68.6)$ & \\
\hline $30-35$ & $252(21.8)$ & $211(22.6)$ & $41(18.4)$ & \\
\hline$>35$ & $166(14.3)$ & $138(14.8)$ & $28(12.6)$ & \\
\hline Unknown & $2(0.2)$ & $1(0.1)$ & $1(0.4)$ & \\
\hline ASA score & & & & $0.064 \ddagger$ \\
\hline 1 or 2 & $543(46.9)$ & $423(45.2)$ & $120(53.8)$ & \\
\hline 3 & $551(47.6)$ & $460(49.2)$ & $91(40.8)$ & \\
\hline 4 or 5 & $25(2.2)$ & $20(2.1)$ & $5(2.2)$ & \\
\hline Unknown & $39(3.4)$ & $32(3.4)$ & $7(3.1)$ & \\
\hline Op time (min) & & & & $<0.001 \ddagger$ \\
\hline$<100$ & $166(14.3)$ & $153(16.4)$ & $13(5.8)$ & \\
\hline $100-199$ & $545(47.1)$ & $454(48.6)$ & $91(40.8)$ & \\
\hline $200-299$ & $228(19.7)$ & $150(16.0)$ & $78(35.0)$ & \\
\hline$\geq 300$ & $36(3.1)$ & $24(2.6)$ & $12(5.4)$ & \\
\hline Unknown & $183(15.8)$ & $154(16.5)$ & $29(13.0)$ & \\
\hline Fused levels (C2-7) & & & & $<0.001 \ddagger$ \\
\hline 1 level & $146(12.6)$ & $113(12.1)$ & $33(14.8)$ & \\
\hline 2 levels & 267 (23.1) & $218(23.3)$ & $49(22.0)$ & \\
\hline 3 levels & $455(39.3)$ & $387(41.4)$ & $68(30.5)$ & \\
\hline 4 levels & $253(21.8)$ & $197(21.1)$ & $56(25.1)$ & \\
\hline 5 levels & $37(3.2)$ & $20(2.1)$ & $17(7.6)$ & \\
\hline LOS (days) & & & & $0.069 \S$ \\
\hline $1-3$ & $443(38.3)$ & $351(37.5)$ & $92(41.3)$ & \\
\hline $4-6$ & $446(38.5)$ & $374(40.0)$ & $72(32.3)$ & \\
\hline $7-9$ & $134(11.6)$ & $105(11.2)$ & $29(13.0)$ & \\
\hline$\geq 10$ & $112(9.7)$ & $83(8.9)$ & $29(13.0)$ & \\
\hline Unknown & $23(2.0)$ & $22(2.4)$ & $1(0.4)$ & \\
\hline Admitting diagnosis (ICD-9-CM code) & & & & $0.045 \S$ \\
\hline Degenerative & $1035(89.4)$ & $837(89.5)$ & $198(88.8)$ & \\
\hline Deformity & $7(0.6)$ & $5(0.5)$ & $2(0.9)$ & \\
\hline Infection & $3(0.3)$ & $3(0.3)$ & $0(0.0)$ & \\
\hline Nonunion & $5(0.4)$ & $2(0.2)$ & $3(1.3)$ & \\
\hline Pathological & $21(1.8)$ & $19(2.0)$ & $2(0.9)$ & \\
\hline Trauma & $58(5.0)$ & $44(4.7)$ & $14(6.3)$ & \\
\hline Other & $8(0.7)$ & $4(0.4)$ & $4(1.8)$ & \\
\hline Unknown & $21(1.8)$ & $21(2.2)$ & $0(0.0)$ & \\
\hline
\end{tabular}

and a median time to operative nonunion of 0.73 years (IQR 0.44-1.57 years). The differences in demographics between the non-BMP and BMP groups were similar except for significant differences in age, ASA scores, opera- tive times, fusion levels, smoking history, and history of diabetes. Unlike the entire cohort, the subset with more than 1 year of follow-up showed no significant differences in admitting diagnosis $(\mathrm{p}=0.087)$ with and without BMP. 
TABLE 1. Demographics of all patients with posterior cervical (subaxial) fusions with and without BMP (continued)

\begin{tabular}{|c|c|c|c|c|}
\hline Demographics & All Cases (\%) & Non-BMP (\%) & $\mathrm{BMP}(\%)$ & p Value* \\
\hline Smoking history & & & & $0.002 \ddagger$ \\
\hline Never & $470(40.6)$ & $396(42.4)$ & $74(33.2)$ & \\
\hline Quit & $509(44.0)$ & $413(44.2)$ & $96(43.0)$ & \\
\hline Current & $168(14.5)$ & $121(12.9)$ & $47(21.1)$ & \\
\hline Unknown & $11(0.9)$ & $5(0.5)$ & $6(2.7)$ & \\
\hline History of diabetes & $352(30.4)$ & $309(33.0)$ & $43(19.3)$ & $<0.001 \ddagger$ \\
\hline
\end{tabular}

Fig. 2 shows Kaplan-Meier curves comparing spinal fusions with and without BMP for the entire study cohort. We found two curves that were not statistically different according to the log-rank test $(\mathrm{p}=0.179)$. For those patients with more than 1 year of follow-up (Table 3), we found 4 nonunions $(0.7 \%)$ in the non-BMP group, and 2 nonunions (1.1\%) in the BMP group. The Fisher's exact test showed no significant difference in nonunion rates between the two groups $(\mathrm{p}=0.621)$.

Due to the low number of nonunions, univariate (crude) logistic regression was employed, comparing nonunion rates for patients without BMP and with BMP separately. The crude odds ratio (Table 3 ) for a nonunion in the BMP versus the non-BMP group for more than 1 year of followup was 1.73 (95\% CI $0.32-9.55, \mathrm{p}=0.527)$. This value suggests that the reoperation rates for nonunions with or without BMP were not statistically significantly different, regardless of the number of levels fused.

\section{Discussion}

Pseudarthrosis rates in posterior cervical fusions have been quoted in the literature as varying from $0 \%$ to $38 \% .6,11,14,21,23,25,28,29$ This large range in nonunion rates reflect variation in patient comorbidities, surgical indications, number of cervical spine levels fused, and the type of instrumentation and bone graft used. The introduction of lateral mass screw-rod fixation systems have biomechanically allowed a more rigid fixation for early bone fusions in the cervical spine. The use of pedicle screws, especially at C-2 and C-7, has increased fixation in the cervical spine. ${ }^{49}$

ICBG has been the gold standard for autograft in spine surgery due to its osteoconductive, osteoinductive, and osteogenic properties, ${ }^{43}$ and is responsible for low nonunion rates in posterior cervical fusions. Another form of autograft, local bone (morcelized lamina), has reduced non-

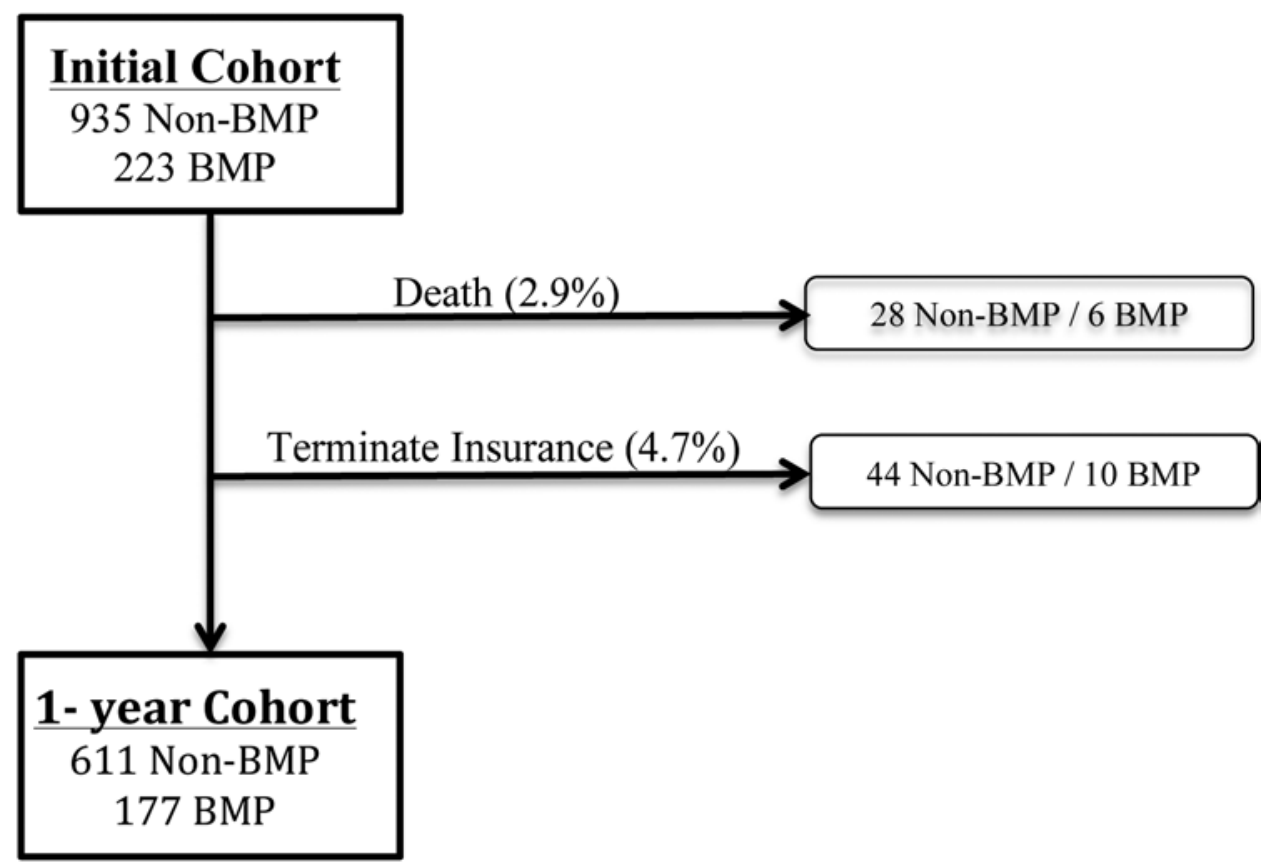

FIG. 1. Chart of the loss to follow-up in the non-BMP and BMP groups for patients who underwent posterior cervical (subaxial) fusion with more than 1 year of follow-up. 
TABLE 2. Demographics of patients with posterior cervical (subaxial) fusions with and without BMP and more than 1 year of follow-up

\begin{tabular}{|c|c|c|c|c|}
\hline Demographics & All Cases (\%) & Non-BMP (\%) & BMP (\%) & $p$ Value* \\
\hline Cases & $788(100.0)$ & $611(77.5)$ & $177(22.5)$ & \\
\hline Age (yrs) & & & & $0.007 \dagger$ \\
\hline Median & 64 & 64 & 61 & \\
\hline IQR & $56-72$ & $56-72$ & $54-69$ & \\
\hline Sex & & & & $0.365 \ddagger$ \\
\hline Female & $324(41.1)$ & $246(40.3)$ & $78(44.1)$ & \\
\hline Male & $464(58.9)$ & $365(59.7)$ & $99(55.9)$ & \\
\hline BMI & & & & $0.391 \S$ \\
\hline$<30$ & $498(63.2)$ & $379(62.0)$ & $119(67.2)$ & \\
\hline $30-35$ & $171(21.7)$ & $136(22.3)$ & $35(19.8)$ & \\
\hline$>35$ & $118(15.0)$ & $96(15.7)$ & $22(12.4)$ & \\
\hline Unknown & $1(0.1)$ & $0(0.0)$ & $1(0.6)$ & \\
\hline ASA score & & & & $0.007 \S$ \\
\hline 1 or 2 & $361(45.8)$ & $263(43.0)$ & $98(55.4)$ & \\
\hline 3 & $379(48.1)$ & $311(50.9)$ & $68(38.4)$ & \\
\hline 4 or 5 & $14(1.8)$ & $10(1.6)$ & $4(2.3)$ & \\
\hline Unknown & $34(4.3)$ & $27(4.4)$ & $7(4.0)$ & \\
\hline Op time (min) & & & & $<0.001 \ddagger$ \\
\hline$<100$ & $113(14.3)$ & $103(16.9)$ & $10(5.6)$ & \\
\hline $100-199$ & $437(55.4)$ & $360(58.9)$ & $77(43.5)$ & \\
\hline $200-299$ & $171(21.7)$ & $107(17.5)$ & $64(36.2)$ & \\
\hline$\geq 300$ & $23(2.9)$ & $13(2.1)$ & $10(5.6)$ & \\
\hline Unknown & $44(5.6)$ & $28(4.6)$ & $16(9.0)$ & \\
\hline Fused levels (C2-7) & & & & $<0.001 \ddagger$ \\
\hline 1 level & $102(12.9)$ & 75 (12.3) & $27(15.3)$ & \\
\hline 2 levels & $195(24.7)$ & $159(26.0)$ & $36(20.3)$ & \\
\hline 3 levels & $298(37.8)$ & $243(39.8)$ & $55(31.1)$ & \\
\hline 4 levels & $168(21.3)$ & $122(20.0)$ & $46(26.0)$ & \\
\hline 5 levels & $25(3.2)$ & $12(2.0)$ & $13(7.3)$ & \\
\hline LOS (days) & & & & $0.051 \S$ \\
\hline $1-3$ & $308(39.1)$ & $232(38.0)$ & $76(42.9)$ & \\
\hline $4-6$ & $285(36.2)$ & $232(38.0)$ & $53(29.9)$ & \\
\hline $7-9$ & $97(12.3)$ & $75(12.3)$ & $22(12.4)$ & \\
\hline$\geq 10$ & $76(9.6)$ & $51(8.3)$ & $25(14.1)$ & \\
\hline Unknown & $22(2.8)$ & $21(3.4)$ & $1(0.6)$ & \\
\hline Admitting diagnosis (ICD-9-CM code) & & & & $0.087 \S$ \\
\hline Degenerative & $703(89.2)$ & $545(89.2)$ & $158(89.3)$ & \\
\hline Deformity & $0(0.0)$ & $0(0.0)$ & $0(0.0)$ & \\
\hline Infection & $2(0.3)$ & $2(0.3)$ & $0(0.0)$ & \\
\hline Nonunion & $4(0.5)$ & $1(0.2)$ & $3(1.7)$ & \\
\hline Pathological & $9(1.1)$ & $8(1.3)$ & $1(0.6)$ & \\
\hline Trauma & $46(5.8)$ & $33(5.4)$ & $13(7.3)$ & \\
\hline Other & $4(0.5)$ & $2(0.3)$ & $2(1.1)$ & \\
\hline Unknown & $20(2.5)$ & $20(3.3)$ & $0(0.0)$ & \\
\hline
\end{tabular}


TABLE 2. Demographics of patients with posterior cervical (subaxial) fusions with and without BMP and more than 1 year of follow-up (continued)

\begin{tabular}{lcccc}
\hline \multicolumn{1}{c}{ Demographics } & All Cases (\%) & Non-BMP (\%) & BMP (\%) & p Value \\
\hline Smoking history & & & & $0.035 \S$ \\
\hline Never & $310(39.3)$ & $252(41.2)$ & $58(32.8)$ & \\
\hline Quit & $347(44.0)$ & $271(44.4)$ & $76(42.9)$ & \\
\hline Current & $122(15.5)$ & $85(13.9)$ & $37(20.9)$ & \\
\hline Unknown & $9(1.1)$ & $3(0.5)$ & $6(3.4)$ & \\
\hline History of diabetes & $232(29.4)$ & $199(32.6)$ & $33(18.6)$ & $<0.001 \ddagger$ \\
\hline
\end{tabular}

\footnotetext{
* Statistically significant values in bold.

$\dagger$ Nonparametric test (Wilcoxon rank-sum).

$\ddagger$ Chi-square test.

$\S$ Fisher exact test.
}

union rates to $9.4 \% .{ }^{23}$ The use of allografts has avoided the complications from harvesting ICBG, $2,15,34,45$ but has not reached the same fusion rates as ICBG. The introduction of BMP, however, has shown in clinical trails that it can be as effective in promoting excellent fusion rates as ICBG in the lumbar spine. ${ }^{1-3}$

Very little has been written about fusion rates in the posterior subaxial cervical spine using BMP (Table 4). The study by Xu et al. ${ }^{47}$ was one of the first on BMP in the subaxial cervical spine, and involved a retrospective review of 156 patients without BMP and 48 with BMP. These investigators had 3 times as many patients in their bob-BMP (control) group compared with the BMP group, which was similar to our study in which the non-BMP group was 4 times as large as the BMP group. All of the patients in the study by Xu et al. had a degenerative spinal disease diagnosis, compared with $89.4 \%$ in our study. These authors used radiographic studies with more than 6 months of follow-up to investigate nonunions. CT imaging in this study showed $0 \%$ with nonunions in the BMP group compared with $12.4 \%$ in the non-BMP group, with an average follow-up duration of $24.2 \pm 10$ months. Statistical significance was demonstrated in favor of higher fusion rates in the BMP group.

Hamilton et al. ${ }^{20}$ presented a more inclusive study of occipitocervical, subaxial cervical, and cervicothoracic posterior fusions with various diagnoses in which BMP was used. In the subaxial spine they identified 53 patients with mean age of 55.7 years, of whom 22 patients had an average of 3 levels fused. There was no control arm (non-BMP) of the study, and 2 independent neuroradiologists assessed bone fusion based on flexion-extension, anteroposterior plain radiographs, and the grading system described by Lenke et al. ${ }^{26}$ for spinal fusions. This study found a nonunion rate of $0 \%$ and concluded that use of BMP as an adjunct for posterior cervical fusion was safe and effective at an average dose of $1.8 \mathrm{mg}$ per level. In our study, the majority of levels fused in both groups was similar to that of Hamilton et al. ${ }^{20}$ with 3 levels (Table 3 ). However, there were slightly more 4-level fusions and 5-level fusions

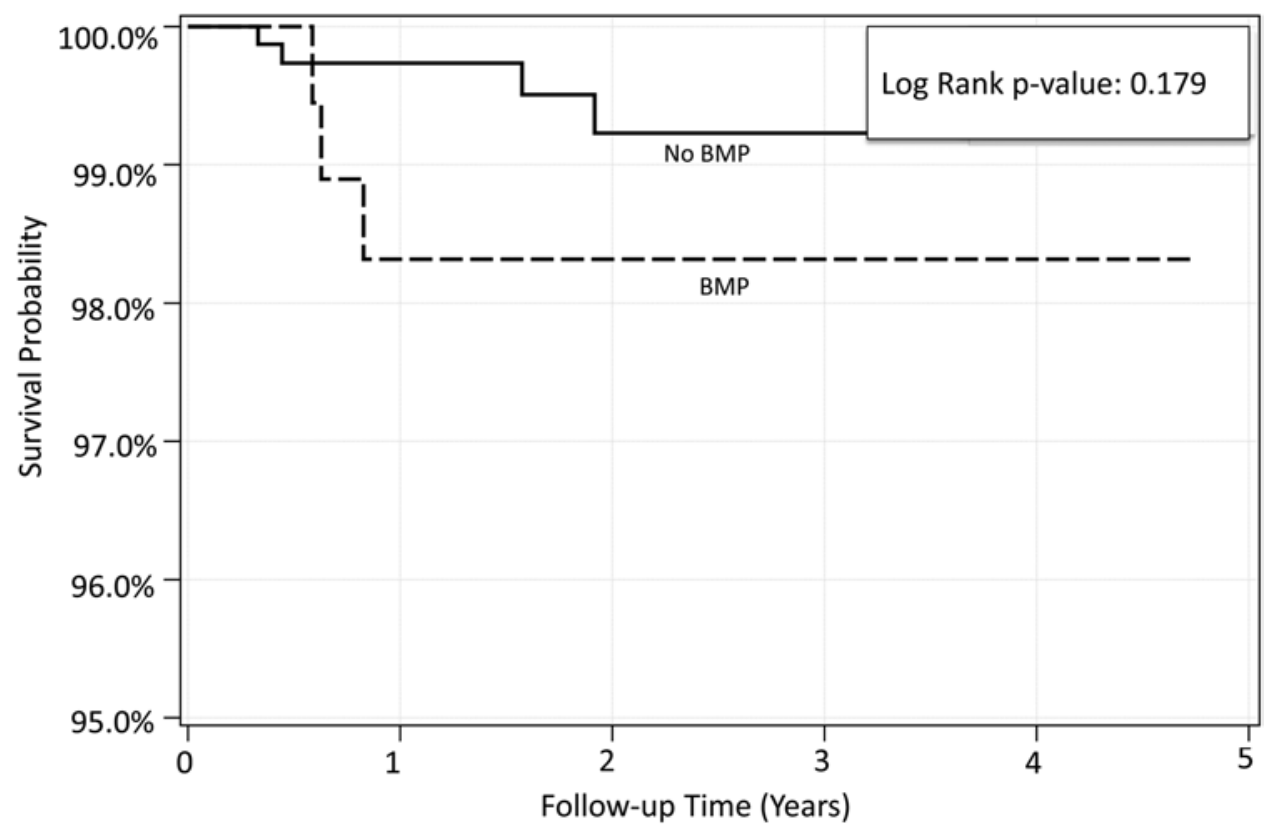

FIG. 2. Kaplan-Meier survival estimates comparing nonunions with and without BMP for the entire cohort of subaxial cervical spine fusions. 
TABLE 3. Comparison of number of levels fused and reoperations for symptomatic nonunions in posterior cervical (subaxial) fusion with and without BMP with more than 1 year of follow-up

\begin{tabular}{lcccccc}
\hline & & \multicolumn{2}{c}{ Cohort (\%) } & & \multicolumn{2}{c}{ Nonunions (\%) } \\
\cline { 3 - 4 } \cline { 6 - 7 } Fused Levels & Total & Non-BMP & BMP & & Non-BMP & BMP \\
\hline 1 level & 102 & $75(12.3)$ & $27(15.3)$ & & $0(0.0)$ & $0(0.0)$ \\
\hline 2 levels & 195 & $159(26.0)$ & $36(20.3)$ & & $1(0.6)$ & $0(0.0)$ \\
\hline 3 levels & 298 & $243(39.8)$ & $55(31.1)$ & & $2(0.8)$ & $1(1.8)$ \\
\hline 4 levels & 168 & $122(20.0)$ & $46(26.0)$ & & $1(0.8)$ & $1(2.2)$ \\
\hline 5 levels & 25 & $12(2.0)$ & $13(7.3)$ & & $0(0.0)$ & $0(0.0)$ \\
\hline Total (C2-7) & 788 & 611 & 177 & & $4(0.7)$ & $2(1.1)$ \\
\hline
\end{tabular}

* The Fisher's exact test was used to test nonunion rate between the BMP and non-BMP groups $(p=0.621)$. The crude $O R$ for a nonunion in the BMP versus non-BMP group was $1.73(95 \% \mathrm{Cl} 0.32-9.55, \mathrm{p}=0.527)$.

in the BMP group, but the number of nonunions was very small and we were unable to determine a significant difference between operative nonunions for the different number of levels fused. Overall, however, there was no significant difference in the total operative nonunions between the groups.

Hodges et al. ${ }^{22}$ prospectively followed 29 patients with posterior subaxial fusions during 12 months with BMP. CT scans were obtained at a minimum of 12 months postoperatively and were evaluated by a neuroradiologist for solid arthrodesis. These investigators found only 3 cases of radiographic nonunions $(10.3 \%)$, but none required surgery (Table 4). They concluded that BMP was associated with increased costs but did not entirely prevent nonunions. Their study indicates a significant difference in operative nonunion rates $(0 \%)$ versus radiographic nonunion rates $(10.3 \%)$. As we previously described, the studies of Dawson et al. ${ }^{12}$ and Singh et al. ${ }^{38}$ found that a radiographic measure of nonunions may be too stringent and not necessarily represent normal clinical practices in which CT scans are routinely obtained and patients are followed for 2 years. Again, we believe operative nonunion rates are useful and clinically relevant and can be used to compare BMP to non-BMP patients.

Dorward et al. ${ }^{13}$ retrospectively reviewed 57 patients who underwent posterior cervical fusions, including occipitocervical, subaxial cervical, and cervicothoracic fusions with BMP. Eleven were identified in the subaxial cervical spine group. The authors found no radiographic evidence of nonunions (Table 4). Their study, however, was significantly different from ours in several ways. The medical histories of the patients in their series were highly complicated; $84.2 \%$ had undergone cervical surgery, and $42.1 \%$ had preexisting pseudarthrosis and therefore BMP was used. Second, their study only involved 2 fellowshiptrained orthopedic spine surgeons, who performed all operations at a single tertiary referral institution. Our study involved more than 91 spine surgeons (neurosurgeons and orthopedic spine surgeons) from community-based hospitals.

We acknowledge there are limitations to our study. It is a retrospective study with inherent selection bias in cases in which BMP was used. For the group with more than 1 year of follow-up, BMP was used in significantly younger patients (61 vs 64 years old), with lower ASA scores, larger percentages in 4-level and 5-level fusions, longer operating times, higher smoking history, and history of diabetes. It should be noted that none of the nonunion cases were performed on smokers, which makes it statistically impossible to assess the association between the covariate smoking history with the outcome of reoperation rates for symptomatic nonunions. Also, we found that for 4-level fusions (Table 3), which was slightly in favor of using BMP (26.0\% vs $20.0 \%$ ), the operative nonunions were higher in the BMP group (2.2\% vs $0.8 \%$ ). Among the 5-level fusions, BMP was used in higher numbers in this group $(7.3 \%$ vs $2.0 \%)$, although there were no operative nonunions in either group. Due to the rarity of nonunions in our cohort, we were limited by our data from making any multivariate adjustments. From an observational point of view, the indications for the use of BMP and its benefits in our cohort raise important questions about its usefulness.

Also, the length of follow-up in our study was more than 1 year, which may be viewed as a shorter period of time for nonunions when compared with lumbar fusions and fusions after deformity surgery. We believe that in the posterior cervical spine, the clinical and radiographic indications of nonunion are much shorter. The median time to nonunion in our entire cohort was 0.63 years (IQR $0.44-$ 1.57 years), which meant that most of the nonunions occurred in the first year. Xu et al. ${ }^{47}$ indicated that the time to nonunion in the posterior cervical spine was greater than 6 months. Hodges et al. ${ }^{22}$ evaluated his patients for nonunion at a minimum of 12 months postoperatively. To account for time-to-event, it was helpful to use the Kaplan-Meier curves. The Kaplan-Meier curves (Fig. 2) showed a log-

TABLE 4. Nonunion rates for posterior cervical (subaxial) fusions from various studies compared with our study

\begin{tabular}{llcc}
\hline & & \multicolumn{2}{c}{ Nonunion \% (Nonunions/Fusions) } \\
\cline { 3 - 4 } Study & Type of Nonunion & Non-BMP & BMP \\
\hline Xu et al., 2011 & Radiographic & $12.4 \%(15 / 121)$ & $0 \%(0 / 48)$ \\
\hline Hamilton et al., 2011* & Radiographic & $\mathrm{NA}$ & $0 \%(0 / 22)$ \\
\hline Hodges et al., 2012† & Operative/radiographic & $\mathrm{NA}$ & $0 \%(0 / 29) / 10.3 \%(3 / 29)$ \\
\hline Dorward et al., $2013^{*}$ & Operative/radiographic & $\mathrm{NA}$ & $0 \%(0 / 11) / 0 \%(0 / 11)$ \\
\hline Present study (>1 yr of follow-up) & Operative & $0.7 \%(4 / 611)$ & $1.1 \%(2 / 177)$ \\
\hline NA $=$ not applicable. & & & \\
$*$ More than 2 years of follow-up. & & & \\
$\dagger$ More than 1 year of follow-up. & & &
\end{tabular}


rank p value of 0.179 , indicating no statistically significant difference in nonunion rates between the BMP and nonBMP groups.

Finally, our study has the advantage of including a large cohort of patients from an integrated health care system's spine registry with no dependence on industry support and featuring varied patient demographics with surgical indications. It also presents one of the largest cohort of patients using BMP in the posterior cervical spine in the literature (Table 4).

\section{Conclusions}

In this study of a cohort of 1158 posterior cervical (C2-7) spinal fusion patients with and without BMP using Kaplan-Meier curves, there was no statistically significant difference in reoperation rates for symptomatic nonunions. For a subset of 788 patients with more than 1 year of follow-up, no difference in reoperations for symptomatic nonunions with and without BMP was found. Our study adds to the literature regarding reoperation rates for symptomatic nonunions from posterior subaxial cervical fusions with and without BMP (1.1\% vs $0.7 \%)$ with more than 1 year of follow-up. This study presents one of the largest cohorts of patients using BMP in the posterior cervical spine.

\section{Acknowledgments}

We thank all of the Kaiser Permanente orthopedic and neurosurgery spine surgeons who contribute to the success of the spine registry as well as the Surgical Outcomes and Analysis department, which coordinates registry operations.

\section{References}

1. Ackerman SJ, Mafilios MS, Polly DW Jr: Economic evaluation of bone morphogenetic protein versus autogenous iliac crest bone graft in single-level anterior lumbar fusion: an evidence-based modeling approach. Spine (Phila Pa 1976) 27 (16 Suppl 1):S94-S99, 2002

2. Ahlmann E, Patzakis M, Roidis N, Shepherd L, Holtom P: Comparison of anterior and posterior iliac crest bone grafts in terms of harvest-site morbidity and functional outcomes. $\mathbf{J}$ Bone Joint Surg Am 84-A:716-720, 2002

3. Anderson DW, Burton DC, Jackson RS: Postoperative cervical myelopathy and cord compression associated with the use of recombinant bone morphogenetic protein-2 in posterior cervical decompression, instrumentation, and arthrodesis: a report of two cases. Spine (Phila Pa 1976) 36:E682-E686, 2011

4. Benzel EC, Zhang DH, Iannotti C, Refai D, Ruggieri P, Krishnaney A: Occipitocervical fusion in an infant with atlantooccipital dislocation. World Neurosurg 78:715.e17-715. e24, 2012

5. Boden SD, Zdeblick TA, Sandhu HS, Heim SE: The use of rhBMP-2 in interbody fusion cages. Definitive evidence of osteoinduction in humans: a preliminary report. Spine (Phila Pa 1976) 25:376-381, 2000

6. Brodsky AE, Khalil MA, Sassard WR, Newman BP: Repair of symptomatic pseudoarthrosis of anterior cervical fusion. Posterior versus anterior repair. Spine (Phila Pa 1976) 17:1137-1143, 1992

7. Burkus JK, Gornet MF, Dickman CA, Zdeblick TA: Anterior lumbar interbody fusion using rhBMP-2 with tapered interbody cages. J Spinal Disord Tech 15:337-349, 2002
8. Cahill KS, Chi JH, Day A, Claus EB: Prevalence, complications, and hospital charges associated with use of bonemorphogenetic proteins in spinal fusion procedures. JAMA 302:58-66, 2009

9. Cahill KS, Chi JH, Groff MW, McGuire K, Afendulis CC, Claus EB: Outcomes for single-level lumbar fusion: the role of bone morphogenetic protein. Spine (Phila Pa 1976) 36:2354-2362, 2011

10. Carragee EJ, Hurwitz EL, Weiner BK: A critical review of recombinant human bone morphogenetic protein-2 trials in spinal surgery: emerging safety concerns and lessons learned. Spine J 11:471-491, 2011

11. Carreon L, Glassman SD, Campbell MJ: Treatment of anterior cervical pseudoarthrosis: posterior fusion versus anterior revision. Spine J 6:154-156, 2006

12. Dawson E, Bae HW, Burkus JK, Stambough JL, Glassman SD: Recombinant human bone morphogenetic protein-2 on an absorbable collagen sponge with an osteoconductive bulking agent in posterolateral arthrodesis with instrumentation. A prospective randomized trial. J Bone Joint Surg Am 91:1604-1613, 2009

13. Dorward IG, Buchowski JM, Stoker GE, Zebala LP: Posterior cervical fusion with recombinant human bone morphogenetic protein-2: complications and fusion rate at minimum two-year follow-up. J Spinal Disord Tech [epub ahead of print], 2013

14. Eubanks JD, Thorpe SW, Cheruvu VK, Braly BA, Kang JD: Does smoking influence fusion rates in posterior cervical arthrodesis with lateral mass instrumentation? Clin Orthop Relat Res 469: 696-701, 2011

15. Fernyhough JC, Schimandle JJ, Weigel MC, Edwards CC, Levine AM: Chronic donor site pain complicating bone graft harvesting from the posterior iliac crest for spinal fusion. Spine (Phila Pa 1976) 17:1474-1480, 1992

16. Fischgrund JS, Mackay M, Herkowitz HN, Brower R, Montgomery DM, Kurz LT: 1997 Volvo Award winner in clinical studies. Degenerative lumbar spondylolisthesis with spinal stenosis: a prospective, randomized study comparing decompressive laminectomy and arthrodesis with and without spinal instrumentation. Spine (Phila Pa 1976) 22:2807-2812, 1997

17. Fu R, Selph S, McDonagh M, Peterson K, Tiwari A, Chou R, et al: Effectiveness and harms of recombinant human bone morphogenetic protein-2 in spine fusion: a systematic review and meta-analysis. Ann Intern Med 158:890-902, 2013

18. Glassman SD, Carreon LY, Campbell MJ, Johnson JR, Puno RM, Djurasovic M, et al: The perioperative cost of Infuse bone graft in posterolateral lumbar spine fusion. Spine J 8:443-448, 2008

19. Guppy KH, Paxton EW, Harris J, Alvarez J, Bernbeck J: Does bone morphogenetic protein change the operative nonunion rates in spine fusions? Spine (Phila Pa 1976) 39:18311839,2014

20. Hamilton DK, Smith JS, Reames DL, Williams BJ, Chernavvsky DR, Shaffrey CI: Safety, efficacy, and dosing of recombinant human bone morphogenetic protein-2 for posterior cervical and cervicothoracic instrumented fusion with a minimum 2-year follow-up. Neurosurgery 69:103-111, 2011

21. Heller JG, Edwards CC II, Murakami H, Rodts GE: Laminoplasty versus laminectomy and fusion for multilevel cervical myelopathy: an independent matched cohort analysis. Spine (Phila Pa 1976) 26:1330-1336, 2001

22. Hodges SD, Eck JC, Newton D: Retrospective study of posterior cervical fusions with rhBMP-2. Orthopedics 35:e895e898, 2012

23. Huang RC, Girardi FP, Poynton AR, Cammisa FP Jr: Treatment of multilevel cervical spondylotic myeloradiculopathy with posterior decompression and fusion with lateral mass plate fixation and local bone graft. J Spinal Disord Tech 16:123-129, 2003 
24. Katz JN, Lipson SJ, Lew RA, Grobler LJ, Weinstein JN, Brick GW, et al: Lumbar laminectomy alone or with instrumented or noninstrumented arthrodesis in degenerative lumbar spinal stenosis. Patient selection, costs, and surgical outcomes. Spine (Phila Pa 1976) 22:1123-1131, 1997

25. Kuhns CA, Geck MJ, Wang JC, Delamarter RB: An outcomes analysis of the treatment of cervical pseudarthrosis with posterior fusion. Spine (Phila Pa 1976) 30:2424-2429, 2005

26. Lenke LG, Bridwell KH, Bullis D, Betz RR, Baldus C, Schoenecker PL: Results of in situ fusion for isthmic spondylolisthesis. J Spinal Disord 5:433-442, 1992

27. Lindley TE, Dahdaleh NS, Menezes AH, Abode-Iyamah KO: Complications associated with recombinant human bone morphogenetic protein use in pediatric craniocervical arthrodesis. J Neurosurg Pediatr 7:468-474, 2011

28. Lovely TJ, Carl A: Posterior cervical spine fusion with tension-band wiring. J Neurosurg 83:631-635, 1995

29. Lowery GL, Swank ML, McDonough RF: Surgical revision for failed anterior cervical fusions. Articular pillar plating or anterior revision? Spine (Phila Pa 1976) 20:2436-2441, 1995

30. Lu DC, Sun PP: Bone morphogenetic protein for salvage fusion in an infant with Down syndrome and craniovertebral instability. Case report. J Neurosurg 106 (6 Suppl):480-483, 2007

31. Ong KL, Villarraga ML, Lau E, Carreon LY, Kurtz SM, Glassman SD: Off-label use of bone morphogenetic proteins in the United States using administrative data. Spine (Phila Pa 1976) 35:1794-1800, 2010

32. Paxton EW, Inacio MC, Kiley ML: The Kaiser Permanente implant registries: effect on patient safety, quality improvement, cost effectiveness, and research opportunities. Perm J 16:36-44, 2012

33. Polly DW Jr, Ackerman SJ, Shaffrey CI, Ogilvie JW, Wang JC, Stralka SW, et al: A cost analysis of bone morphogenetic protein versus autogenous iliac crest bone graft in single-level anterior lumbar fusion. Orthopedics 26:1027-1037, 2003

34. Sawin PD, Traynelis VC, Menezes AH: A comparative analysis of fusion rates and donor-site morbidity for autogeneic rib and iliac crest bone grafts in posterior cervical fusions. J Neurosurg 88:255-265, 1998

35. Shahlaie K, Kim KD: Occipitocervical fusion using recombinant human bone morphogenetic protein-2: adverse effects due to tissue swelling and seroma. Spine (Phila Pa 1976) 33:2361-2366, 2008

36. Simmonds MC, Brown JV, Heirs MK, Higgins JP, Mannion RJ, Rodgers MA, et al: Safety and effectiveness of recombinant human bone morphogenetic protein-2 for spinal fusion: a meta-analysis of individual-participant data. Ann Intern Med 158:877-889, 2013

37. Singh K, Nandyala SV, Marquez-Lara A, Fineberg SJ: Epidemiological trends in the utilization of bone morphogenetic protein in spinal fusions from 2002 to 2011. Spine (Phila Pa 1976) 39:491-496, 2014

38. Singh K, Phillips FM, Park DK, Pelton MA, An HS, Goldberg EJ: Factors affecting reoperations after anterior cervical discectomy and fusion within and outside of a Federal Drug Administration investigational device exemption cervical disc replacement trial. Spine J 12:372-378, 2012

39. Smucker JD, Rhee JM, Singh K, Yoon ST, Heller JG: Increased swelling complications associated with off-label usage of rhBMP-2 in the anterior cervical spine. Spine (Phila Pa 1976) 31:2813-2819, 2006

40. Stachniak JB, Diebner JD, Brunk ES, Speed SM: Analysis of prevertebral soft-tissue swelling and dysphagia in multilevel anterior cervical discectomy and fusion with recombinant human bone morphogenetic protein-2 in patients at risk for pseudarthrosis. J Neurosurg Spine 14:244-249, 2011

41. Thawani JP, Wang AC, Than KD, Lin CY, La Marca F, Park $P$ : Bone morphogenetic proteins and cancer: review of the literature. Neurosurgery 66:233-246, 2010

42. US Food and Drug Administration: FDA Public Health Notification: Life-Threatening Complications Associated with Recombinant Human Bone Morphogenetic Protein in Cervical Spine Fusion. Silver Spring, MD: US Food and Drug Administration, 2008 (http://www.fda.gov/MedicalDevices/Safety/AlertsandNotices/PublicHealthNotifications/ ucm062000.htm) [Accessed October 9, 2015]

43. Vaccaro AR, Chiba K, Heller JG, Patel TC, Thalgott JS, Truumees E, et al: Bone grafting alternatives in spinal surgery. Spine J 2:206-215, 2002

44. Vaccaro AR, Patel T, Fischgrund J, Anderson DG, Truumees E, Herkowitz HN, et al: A pilot study evaluating the safety and efficacy of OP-1 Putty (rhBMP-7) as a replacement for iliac crest autograft in posterolateral lumbar arthrodesis for degenerative spondylolisthesis. Spine (Phila Pa 1976) 29:1885-1892, 2004

45. Vaidya R, Carp J, Sethi A, Bartol S, Craig J, Les CM: Complications of anterior cervical discectomy and fusion using recombinant human bone morphogenetic protein-2. Eur Spine J 16:1257-1265, 2007

46. Williams BJ, Smith JS, Fu KM, Hamilton DK, Polly DW Jr, Ames CP, et al: Does bone morphogenetic protein increase the incidence of perioperative complications in spinal fusion? A comparison of 55,862 cases of spinal fusion with and without bone morphogenetic protein. Spine (Phila Pa 1976) 36:1685-1691, 2011

47. Xu R, Bydon M, Sciubba DM, Witham TF, Wolinsky JP, Gokaslan ZL, et al: Safety and efficacy of rhBMP2 in posterior cervical spinal fusion for subaxial degenerative spine disease: analysis of outcomes in 204 patients. Surg Neurol Int 2:109, 2011

48. Yaremchuk KL, Toma MS, Somers ML, Peterson E: Acute airway obstruction in cervical spinal procedures with bone morphogenetic proteins. Laryngoscope 120:1954-1957, 2010

49. Yoshimoto H, Sato S, Hyakumachi T, Yanagibashi Y, Masuda $\mathrm{T}$ : Spinal reconstruction using a cervical pedicle screw system. Clin Orthop Relat Res (431):111-119, 2005

\section{Disclosures}

The authors report no conflict of interest concerning the materials or methods used in this study or the findings specified in this paper.

\section{Author Contributions}

Conception and design: Guppy, Bernbeck. Acquisition of data: Guppy, Harris, Alvarez. Analysis and interpretation of data: Guppy, Harris, Alvarez. Drafting the article: Guppy. Critically revising the article: Guppy, Harris, Chen, Paxton, Bernbeck. Reviewed submitted version of manuscript: Guppy, Chen, Paxton. Approved the final version of the manuscript on behalf of all authors: Guppy. Statistical analysis: Guppy, Harris, Chen, Alvarez. Administrative/technical/material support: Guppy, Harris, Paxton, Alvarez, Bernbeck. Study supervision: Guppy.

\section{Correspondence}

Kern H. Guppy, Department of Neurosurgery, Kaiser Permanente Medical Group, 2025 Morse Ave., Sacramento, CA 95825-2115. email: kguppy@yahoo.com. 